\title{
Effects of Waste Plastic Oil Blends on a Multi Cylinder Spark Ignition Engine
}

\author{
Kareddula Vijaya Kumar ${ }^{1}$, Ravi Kumar Puli ${ }^{2}$ \\ ${ }^{1}$ Research Scholar, MED, National Institute of Technology, Warangal, TS-506004, India \\ ${ }^{2}$ Professor, MED, National Institute of Technology, Warangal, TS-506004, India
}

\begin{abstract}
Existing fossil fuels are utilizing at their critical rate, leads to depletion of their reserves in a dramatic way. Generating alternative energy sources in a pragmatic way are necessitated, which demands the researchers to utilize the inherent energy of carbon based products as an energy source to the automobile sector. As a part of it, my research is focused on transforming and using the waste plastics as an alternative fuel in multi cylinder spark ignition engine. This paper aims to present the experimental investigations of performance and emission characteristics in an existing Maruti 800 petrol engine running with the blends of 5\%, 10\%, 15\% and 20\% of waste Plastic Pyrolysis Oil (PPO) with gasoline. From the results, it is noticed that hydrocarbon emissions are substantially reduced and oxides of nitrogen emissions are increased and petrol engine can operate with PPO blends up to $20 \%$ without any engine modifications.
\end{abstract}

\section{Introduction}

The rapid industrialization and rushing of automobile sector has led to a steep rise in the demand of petroleum based fuels. As a result, the reserves of the fossil fuels are rapidly exhausting. Scientist estimated that, known petroleum reserves to be depleted in less than 50 years with the present rate of consumption. It forewarns the research community regarding the shortage of energy by the shortage of finite fossil fuel reserves. Besides designing the efficient engines, it needs to search for the substitute of the current using fuels to fulfil future demands. Disposal of waste plastics is causing serious problem to the environment and mankind. Therefore, present work aims to conserving the energy from the waste plastic into needful form of fuel in internal combustion engines. Pyrolysis is the process of thermally degrading long chain polymer molecules into smaller, less complex molecules through heat and pressure. The process requires intense heat with shorter duration in the absence of oxygen. The three major products that are produced during pyrolysis are oil, gas and char which are valuable for industries especially production and refineries. Pyrolysis was chosen by many researchers since the process able to produce high amount of liquid oil up to $80 \mathrm{wt} \%$ at moderate temperature around 450 $500^{\circ} \mathrm{C}$ and also reviewed the recycling of solid wastes and suggested chemical recycling to control the environmental issues [1-3]. [4-8] Experimental investigation was carried out on a compression ignition engine with waste plastic oil and tyre oil blends with and without exhaust gas recirculation. Their experimental report clearly indicates that the engines which are run with plastic oil and tyre oil releases large amount of $\mathrm{NO}_{\mathrm{x}}$ emission, which can minimise by using exhaust gas recirculation. KareddulaVijaya Kumar et al. [9] experimental studies with distilled plastic pyrolysis oil as an alternate fuel for spark ignition engine. Their results show that $50 \%$ distilled plastic pyrolysis oil was gave enhancement in performance compared with petrol and other blends even at full load conditions. The main objective of this research work is defined as an extension of earlier research, most of experimental investigations carried out with plastic pyrolysis oil operated on compression ignition engines and very minimum work was carried out on spark ignition engines. Analyse the engine performance and emission characteristics of three cylinder Maruti 800 petrol engine fuelled with waste plastic oil blends with gasoline at different volume fractions.

\subsection{Pyrolysis process of waste plastics}

Waste plastic is non-biodegradable nature and it contains toxic chemicals which consumption is harm full to cattle. According to the Central Pollution Control Board (CPCB), India produces 5.6 million tons of plastic waste yearly and solitary $60 \%$ of this waste is recycled presently. Even though there are eco-friendly substitutes for some plastics, they are not as versatile or durable as plastics. So it's becoming inevitable to use them in daily life, but need to reduce its utilization rate. Even though increase the reuse and recycling of plastic waste produced are crucial. Opportunely, there is thought-provoking idea 
to convert carbon chain plastic waste into petroleum grade fuel as shown in Fig.1. Pyrolysis is the chemical decomposition of condensed organic materials by heating in a reactor, largely in the absence of oxygen. The Pyrolysis mainly uses a straw, branches, sawdust and other agricultural and forestry waste as raw material and, through high temperature and pressure, forms the raw materials into a variety of products. Depending on the pyrolysis method, residence time, the temperature to which the waste plastics are exposed, and the characteristics of the waste plastics, varying proportions of gas, liquid and solid products can be produced.

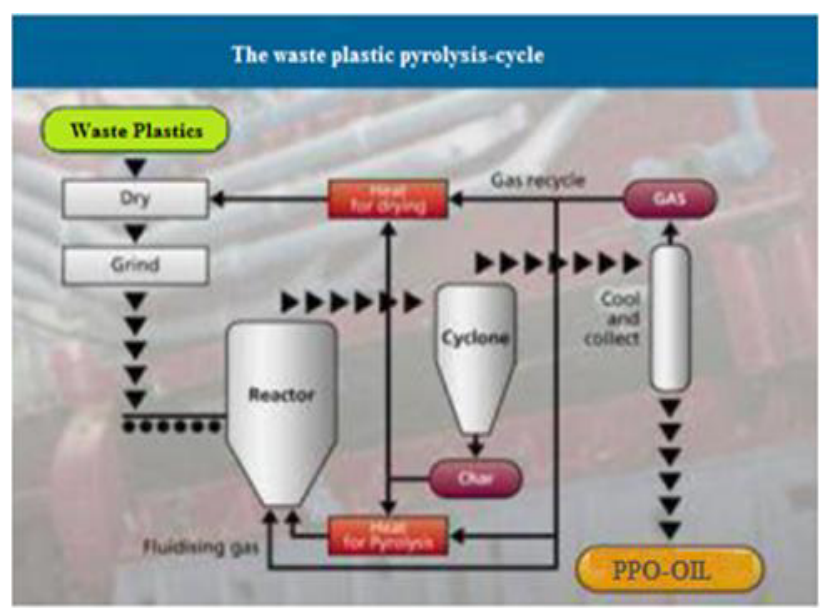

Figure 1. Pyrolysis process of waste plastics

\subsection{Blending machine apparatus}

The emulsifier is a blending apparatus as shown in Fig. 2, used for homogenize the waste plastic pyrolysis oilgasoline blends at desired proportions. The homogeniser apparatus was supplied by Ormeroo Engineers Limited, England. So, the prepared plastic pyrolysis oil blends for investigating the nature and performance of emissions by a spark ignition engine.

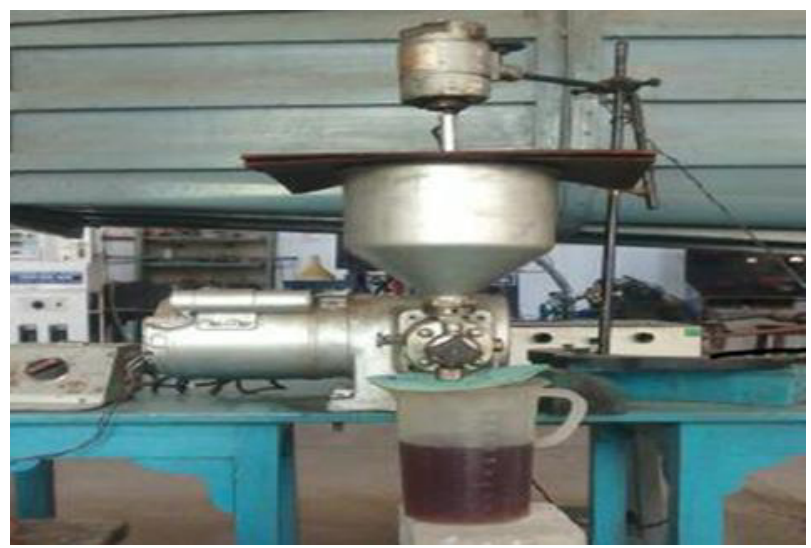

Figure 2. Blending Machine Apparatus

\subsection{Preparation of plastic pyrolysis oil blends}

The basic properties of PPO-PF were measured and compared to conventional petroleum fuel. The Carbon content is higher for PPO than petrol fuel. In the present work 5 PPO, 10 PPO, 15 PPO and 20 PPO of PPO was blended with petrol fuel on a volume basis and observed for 15 days to check for any separation. No such separation was noticed. PPO blended with PF is indicated as 15 PPO. For example, $15 \%$ PPO blended with $85 \%$ PF is denoted as 15 PPO. The estimated PPO flash and fire point are 40 and 44 respectively. The basic properties of plastic oil compared with petrol are in Table 1.

Table 1. Basic properties of fuels

\begin{tabular}{|l|l|l|l|}
\hline $\begin{array}{l}\text { S. } \\
\text { No. }\end{array}$ & Characteristics & Petrol & PPO \\
\hline 1 & Specific Gravity & 0.741 & 0.83 \\
\hline 2 & $\begin{array}{l}\text { Kinematic Viscosity } \\
\mathrm{mm}^{2} / \mathrm{sec}\end{array}$ & 0.5 & 2.64 \\
\hline 3 & Calorific Value $(\mathrm{KJ} / \mathrm{kg})$ & 43449.7 & 42807.5 \\
\hline 4 & Density $\left(\mathrm{kg} / \mathrm{m}^{3}\right)$ & 740.82 & 830 \\
\hline
\end{tabular}

\section{Experimental setup}

Experiments were conducted on a three cylinder Maruti 800 petrol engine with a fixed compression ratio at a constant speed of $1500 \mathrm{rpm}$ under different loads. The experimental setup is as shown in Fig. 3, it consists of three cylinder, 4-stroke, water cooled engine. A water brake dynamometer has been used in the present study to load the engine. The main principle of operation of the dynamometer is water acts as a cooling and loading medium. The running rotor causes the water to whirl in the chamber. The braking energy thus absorbed converts to heat, which is dissipated with circulating water. At a given constant speed of the dynamometer its reaction torque is a function of water value in the whirl chamber, which in turn is controlled by a sluice gate. It has a provision of digital load indicator for the display of load while loading the engine. A U-tube manometer is used to note the difference between the pressure head to calculate the air flow rate.

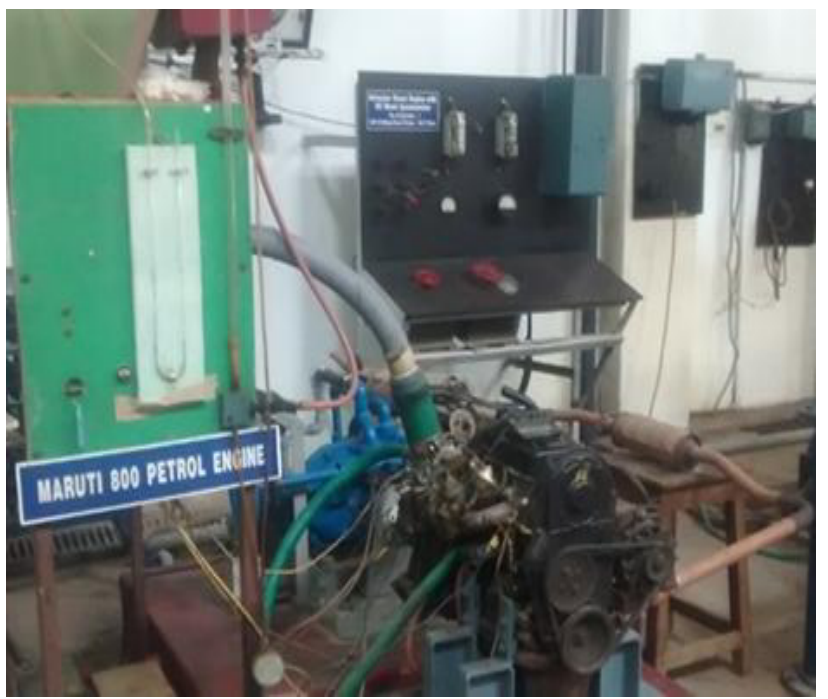

Figure 3. Schematic of Maruti 800 Petrol Engine Test Setup

\subsection{AVL five gas analyser}

The purpose of the AVL gas 444 is to measure the relative volumes of certain gases constituents in the five 
exhaust gas of motor vehicles has shown in Fig. 4. These gases are carbon monoxide, carbon dioxide, hydrocarbons, and oxygen nitric oxide. The air fuel ratio is calculated from the Carbon Monoxide $(\mathrm{CO})$, Carbon Dioxide $\left(\mathrm{CO}_{2}\right)$, Hydrocarbons $(\mathrm{HC})$ and Oxygen $\left(\mathrm{O}_{2}\right)$, constituents and displayed. The Liquid crystal display shows the constituents of the gas once the gas is allowed to flow in. It is a standard output device for the AVL gas 444.

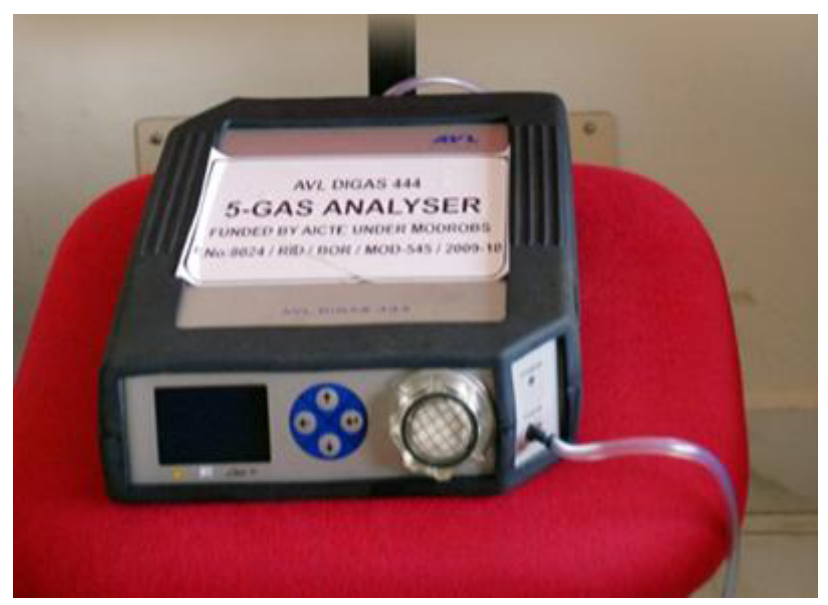

Figure 4. AVL Five Gas Analyser

\section{Results and discussions}

The influencing parameters such as Brake Specific Fuel Consumption (BSFC), Brake Thermal Efficiency (BTE) were presented on the performance of the petrol engine. Fig. 5 elucidates the influence of the brake power on the brake specific fuel consumption. The fuel consumption rate is increased uniformly as a function of blending proportions. At starting loading condition (0 to $0.5 \mathrm{~kW})$, the variation of the BSFC is drastically increased after that a sudden decrease in BSFC along with the variation of brake power for petrol and other plastic oil blends. $25.53 \%$ BSFC augment was noticed at 20 PPO blend when compared with baseline petrol. Fig. 6 illustrates the brake thermal efficiency as a function of brake power. The BTE is linearly varied up to $2 \mathrm{~kW}$ brake power, after that it varies parabolically along with the brake power, and this variation is depending on blend proportions. At the full load conditions, the BTE was decreasing with increment in blend, proportions due to the lower calorific value of the plastic pyrolysis oil. Maximum decrement of $19.24 \%$ at 20 PPO compared to gasoline at full load conditions.

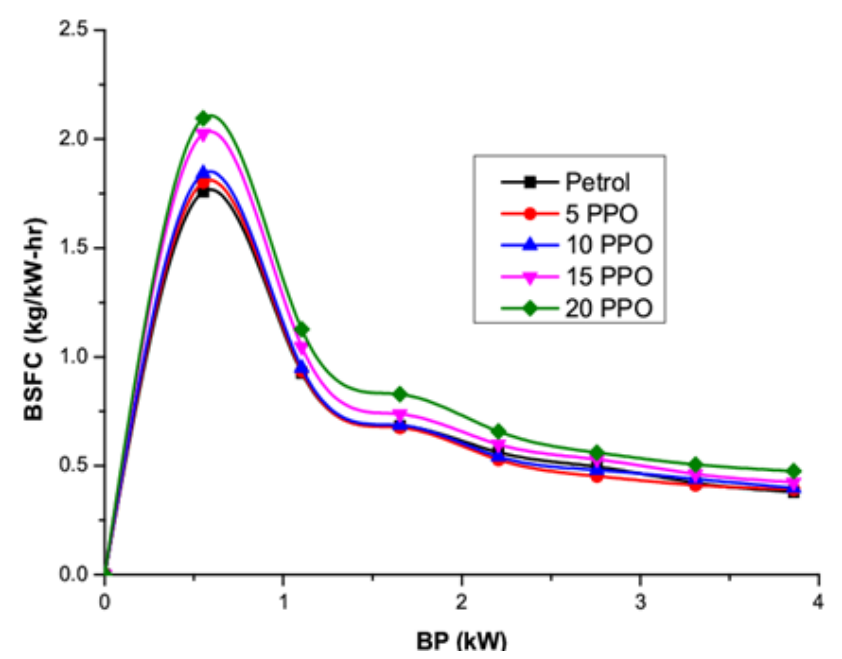

Figure 5. Variation of BSFC with Brake Power

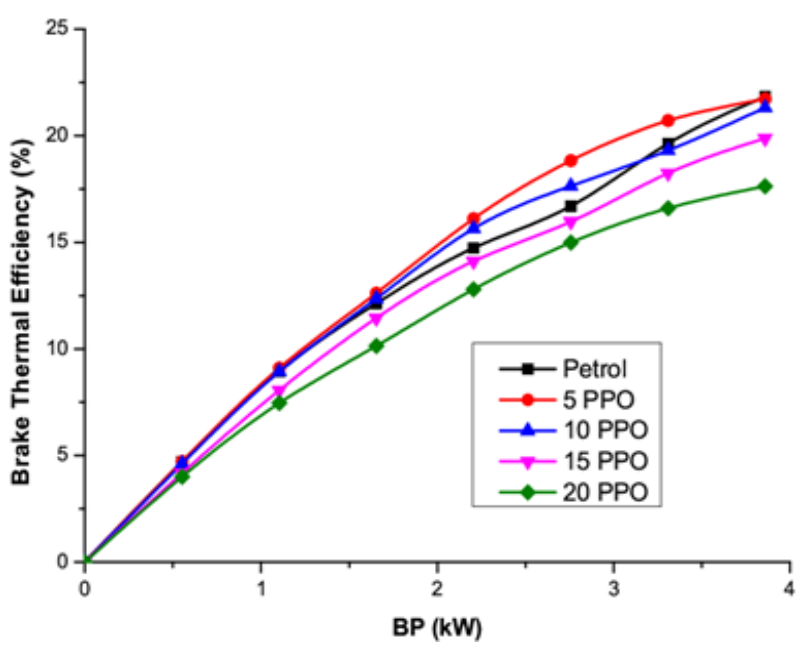

Figure 6. Variation of BTE with Brake Power

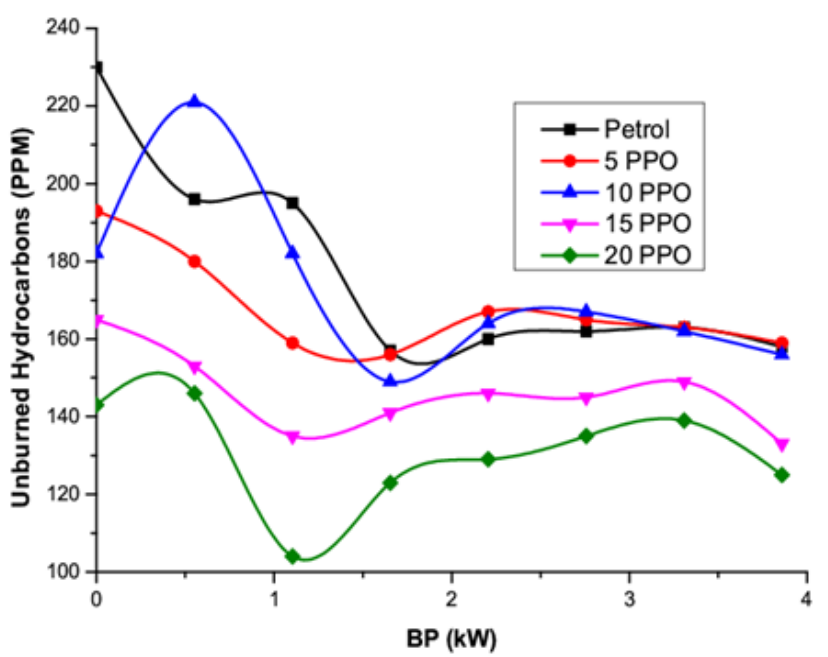

Figure 7. Variation of $\mathrm{HC}$ with Brake Power 


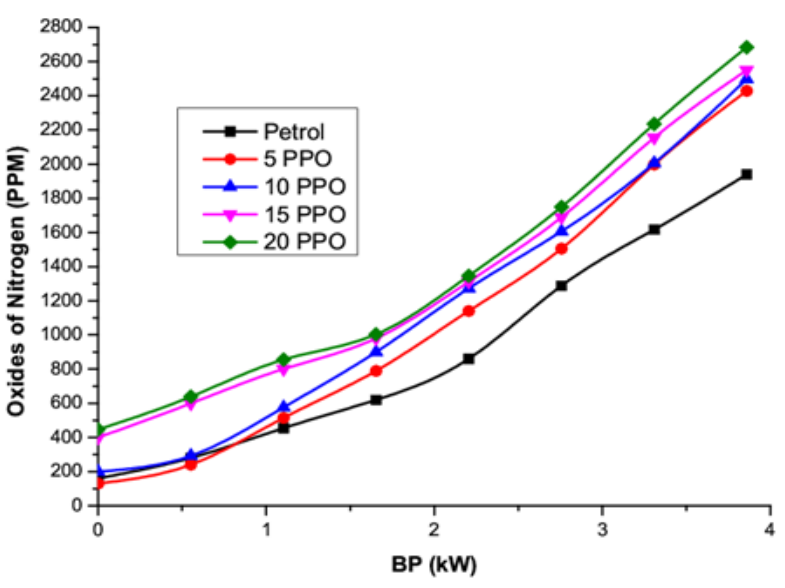

Figure 8. Variation of $\mathrm{NO}_{x}$ with Brake Power

Major constituents of engine emissions are $\mathrm{CO}, \mathrm{O}_{2}$, $\mathrm{CO}_{2}$, unburned $\mathrm{HC}, \mathrm{NO}_{\mathrm{x}}$ and particulate matter. The effect of $\mathrm{HC}$ emissions using different gasoline blends is as shown in Fig. 7. The root cause for the formation of the $\mathrm{HC}$ emissions is unburned mixture of PPO blended gasoline. Some of the air fuel mixture pockets were not participating in the combustion hence, it gives rise to unburned $\mathrm{HC}$ emissions due to misfires and $\mathrm{HC}$ deposits. When compared to pure gasoline, there is a significant decrement in the unburned $\mathrm{HC}$ emissions for the all PPO blends. Fig. 8 it is noticed that, $\mathrm{NO}_{\mathrm{x}}$ emissions are increasing with increase in the peak cylinder temperature by an increase in load. $\mathrm{NO}_{\mathrm{x}}$ emissions are also varying with air fuel ratio, as the blend proportion increases air fuel ratio also increased and hence more amount of nitrogen is admitted into the engine cylinder in terms of more air intake. This admitted nitrogen will not participate in combustion process, but react with oxygen and generates oxides of nitrogen. These nitrogen oxide emissions are uniformly increasing with the blend proportion.

\section{Conclusions}

The engine performance and emission characteristics of PPO with gasoline blends are experimentally measured and reported. PPO blends are tested on three cylinder Maruti 800 petrol engine test rig and emissions are measured with AVL 5 gas analyser. To conduct the experiments, the plastic pyrolysis oil is blended with petrol using blending apparatus. The thermo physical chemical properties of all blends are closer to the gasoline properties. The experimental outcomes clears that, the brake specific fuel consumption of the engine fuelled with 20 PPO is $25.52 \%$ higher than that of the engine fuelled with sole gasoline at full load. 19.24\% lesser brake thermal efficiency is obtained for 20PPO compared to gasoline. The unburned hydrocarbon emissions are marginally reduced to $25.56 \%$ for $20 \mathrm{PPO}$. The $\mathrm{NO}_{\mathrm{x}}$ emissions are $29.13 \%$ more in the 20 PPO compared to that of the engine fuelled with $100 \%$ gasoline as fuel. In the view of performance, experiments can run beyond $20 \%$ plastic pyrolysis oil without altering the engine designs. But, as the PPO increased beyond
$20 \%$ is responsible for higher $\mathrm{NO}_{\mathrm{x}}$ emissions, which cross the EPA norms and augmentation in viscosity causes for higher surface tension and reduction in flowability of fuel in orifice.

\section{References}

1. BeheraPritinika, Murugan S, Combustion, performance and emission parameters of used transformer oil and its diesel blends in a DI diesel engine, Fuel 104, (2013) pp. 147-154.

2. Mehdi Sadat-Shojai, Gholam Reza Bakhshandeh, Recycling of PVC wastes, Polymer Degradation and Stability 96, Elsevier, (2011), pp. 404-415.

3. Murugan, S., Ramaswamy, M.C., Nagarajan, G., Production of Tyre Pyrolysis Oil from Waste Automobile Tyres, In the Proceedings of National conference on Advances in Mechanical Engineering, (2006), 899-906.

4. M Paul Daniel, KareddulaVijaya Kumar, B Durga Prasad, Performance and Emission Characteristics of Diesel Engine Operated on Tyre Pyrolysis Oil with exhaust gas recirculation, International Journal of Ambient Energy (IJAE), Taylor and Francis, August (2015), DOI: 10.1080/01430750.2015.1023837.

5. KareddulaVijaya Kumar, Ravi Kumar Puli, Monika Dixit, D Ravi Chandra, Performance and Emission Evaluation of Tyre Oil blended with Diesel Fuel in Compression Ignition Engine, International Conference on Environment and Energy (ICEE2014), December (2014), JNTUH Kukatpally, Hyderabad, India.

6. M Paul Daniel, KareddulaVijaya Kumar, B Durga Prasad, Ravi Kumar Puli, Performance and Emission Characteristics of Diesel Engine Operated on Plastic Pyrolysis Oil with exhaust gas recirculation, IJAE, Taylor and Francis, September (2015), DOI: 10.1080/01430750.2015.1086677.

7. KareddulaVijaya Kumar, Ravi Kumar Puli, A VeereshBabu, J. A. RangaBabu, Performance and Emission Evaluation of Plastic Oil blended with Diesel Fuel in Compression Ignition Engine, International Conference on Environment and Energy (ICEE-2014), December (2014), JNTUH Kukatpally, Hyderabad, India.

8. K. Vijaya Kumar, Dr. Ravi Kumar Puli, D. Ravichandra, K. Abhishek, Investigation on a CI Engine Fuelled with blends of Waste Tyre oil, Third International Conference on Advances in Mechanical, Aeronautical and Production Techniques (MAPT), April (2015), Malaysia.

9. KareddulaVijaya Kumar, Ravi Kumar Puli, A SwarnaKumari, P Shailesh, "Performance and Emission Studies of a SI Engine using Distilled Plastic Pyrolysis Oil-Petrol Blends", MATEC Web of Conferences 45, 03002 (2016), DOI: 10.1051/matecconf/20164503002. 